\title{
Article \\ Electromyographic Analysis of Exercises on a Gymnastic Horse and a Walking Horse: A Pilot Study
}

\author{
Barbora Pyšková ${ }^{1,2,3, * \mathbb{D}}$, Tereza Nováková ${ }^{3}$, Radka Bačáková ${ }^{4}$ and Miloslav Vilímek $^{5}(\mathbb{D}$ \\ 1 Department of Anatomy and Biomechanics, Faculty of Physical Education and Sport, Charles University, \\ 16252 Prague, Czech Republic \\ 2 Bodytherapist, Klánovická 487, 19800 Prague, Czech Republic \\ 3 Department of Physiotherapy, Faculty of Physical Education and Sport, Charles University, \\ 16252 Prague, Czech Republic; tnovakova@ftvs.cuni.cz \\ 4 Department of Outside Sports, Faculty of Physical Education and Sport, Charles University, \\ 16252 Prague, Czech Republic; bacakova@ftvs.cuni.cz \\ 5 Laboratory of Biomechanics, Department of Mechanics, Biomechanics and Mechatronics, Faculty of \\ Mechanical Engineering, Czech Technical University in Prague, 16636 Prague, Czech Republic; \\ miloslav.vilimek@fs.cvut.cz \\ * Correspondence: pyskovax@ftvs.cuni.cz
}

check for

updates

Citation: Pyšková, B.; Nováková, T.; Bačáková, R.; Vilímek, M.

Electromyographic Analysis of

Exercises on a Gymnastic Horse and a Walking Horse: A Pilot Study. Appl.

Sci. 2021, 11, 11352. https://doi.org/ 10.3390/app112311352

Academic Editor: José

A. González-López

Received: 26 September 2021

Accepted: 24 November 2021

Published: 30 November 2021

Publisher's Note: MDPI stays neutral with regard to jurisdictional claims in published maps and institutional affiliations.

Copyright: (c) 2021 by the authors. Licensee MDPI, Basel, Switzerland. This article is an open access article distributed under the terms and conditions of the Creative Commons Attribution (CC BY) license (https:/ / creativecommons.org/licenses/by/ $4.0 /)$.
Featured Application: Improving the riding seat with the help of exercises simulating the effect of a living horse would represent a considerable benefit for beginner riders.

Abstract: In studies testing the effect of hippotherapy on the human body, no one has yet compared the involvement of the same specific muscles in exercises on a gymnastic (pommel) horse vs. a walking horse. To improve the correct riding seat and to compare the differences in electromyographic activity, we conducted an experimental study to measure the activity of selected muscles on a set of probands of both sexes during three exercises on a gymnastic horse vs. a walking horse. We measured the activity of eight selected muscles, expressed as the percentage value of the maximal voluntary contraction. Maximal voluntary contraction of each muscle was electromyographically measured using Janda's strength muscle test. These values were used as a standard for values obtained from exercising on a gymnastic horse and a walking horse. The effect of the studied factors was tested by analysis of variance. The muscle activity was statistically significantly affected by the studied factors. It was higher when riding a living horse than a gymnastic horse and in females compared to males. Although the exercises on a gymnastic horse generated lower muscle activity than those on a walking horse, there was a variation among individual muscles that justified further study.

Keywords: horse riding therapy; gymnastic horse; EMG; electromyography; hippotherapy; correct riding seat

\section{Introduction}

Hippotherapy is making use of biomechanic similarities between horse and human gaits [1,2]. Correct seating is an essential requirement for hippotherapeutic horseback riding; still, it can be adapted to the specific needs of each rider [1]. The rider's seat on a walking horse is very similar to that on a standing horse. The rider should always form the imaginary straight line of the ear, shoulder, hip, and heel [3]. Two types of seats are distinguished on horses, i.e., working and light seats $[4,5]$. In more demanding runs, the rider must be stable in a light seat; their center of gravity is always above the horse, and adductors have to deliver enhanced performance [6].

Maintaining the body position in response to gravitation is an automatic mechanism that appears in the early postnatal period due to the maturation of the central nervous system (CNS). By sitting on a moving horse's back, the CNS is stimulated, and an effort is made to straighten the trunk to maintain balance [7]; this effort is more intense than 
in regular sitting. When sitting on horseback, the sitting area is closely related to the position of the pelvis and root joints (hips) in the caudal direction and the straightening of the trunk in the cranial direction. The movement of the horse then affects and changes the sitting area of the rider according to the speed and direction of the ride. Adaptation to sitting conditions (e.g., the movement of a horse) is a cognitive process based on (i) immediate reactions of the CNS to control the position and movement; (ii) voluntary correction mechanisms, resulting from, e.g., instruction from a therapist or a coach, (iii) increasing the effectiveness of feedback mechanisms leading to improved coordination, and (iv) transfer to automatically controlled exercise programs [7].

From the kinesiological point of view, various muscles are involved in the extension and flexion of the axial system during the rider's movement on a horse [8]. Both superficial and deep abdominal and back muscles are considered essential for the maintenance of an upright and stable sitting position on horseback due to their stabilization and antagonistic function [6]. The ideal muscle engagement is even on both sides. Most people are unilaterally overburdened, whether at work or in other activities. In horseback riding, be it sport, recreational, or therapeutic, it is very important to compensate as much as possible for muscle and physical imbalances; this can be achieved through preparatory exercises, strengthening, stretching, and various other tools [7,9-13].

Although some recent studies have tested the effect of hippotherapy on the human body, none has yet compared the involvement of the same specific muscles in exercises on a gymnastic horse vs. a walking horse. Studies have compared correct riding seats in equestrian sports and hippotherapy [1], explored the effect of hippotherapy on the muscle activity of the trunk and upper limb muscles during sitting, standing, and walking [14], or addressed how to improve the stability of the trunk $[15,16]$. Some studies have addressed the therapeutic effects of hippotherapy, e.g., after cerebral palsy [17,18], stroke [19], or in patients with vertebrogenic algic syndrome [20]. The influence of horses on cognitive functions was described by Ohtani et al. [21], who found that the vibrations caused by the horse's movement led to activation of the sympathetic nervous system in children.

Despite the great potential of joint use of equestrian therapy and physiotherapy to influence the function of the musculoskeletal system, hippotherapy or hipporehabilitation are still not widely used in the Czech Republic. Since the correctly performed riding seat is essential not only in sport or recreation horseback-riding but also in therapeutic riding and for rider's interaction with the horse, we focused on preparatory exercises designed to improve the correct riding seat. Our goal was to (i) measure the activity of selected muscles, expressed as a percentage of the maximum free capacity on a set of probands of both sexes during exercises; and (ii) to determine whether the activity of the selected muscles during the performed exercises differs depending on the applied treatment (walking horse vs. gymnastic horse). For this purpose, we test two hypotheses: Hypothesis 1: The activity of selected muscles during the performed exercises will vary depending on the specific muscle, proband, and tested factors. Hypothesis 2: The activity of selected muscles during the performed exercises will differ depending on the treatment (walking horse, gymnastic horse), while during exercise on a horse in step, it will be higher than during the exercise on a gymnastic horse.

\section{Material and Methods}

The study was approved by the ethics committee of the Faculty of Physical Education and Sport of Charles University on 3 August 2017 under number 040/2017 and was conducted in accordance with the principles set forth in the Helsinki Declaration. Each proband was informed in advance about all measurements and how the results will be processed and interpreted, signed informed consent, and participated in the research voluntarily. 


\subsection{Selection of Probands}

The measurements were performed on four women and five men, selected to meet the following criteria: (i) age between 25 and 30 years; (ii) with no history of acute or chronic musculoskeletal disorders; (iii) no previous experience of regular horse riding; (iv) and showing no signs of general fatigue, mental and physical overload.

\subsection{Exercises to Correct the Riding Seat}

The following exercises were used from riding seat position:

Exercise 1 (elevation of the knees) - flexion in the right hip joint with the bent knee (for two sec) - the right lower limb into the starting position-flexion in the left hip joint with the bent knee (for two sec) - the left lower limb into the starting position-flexion in both hip joints with bent knees (for two sec)—lower limbs into the starting position (Figure 1B).

A

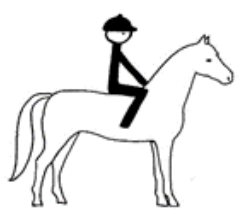

B
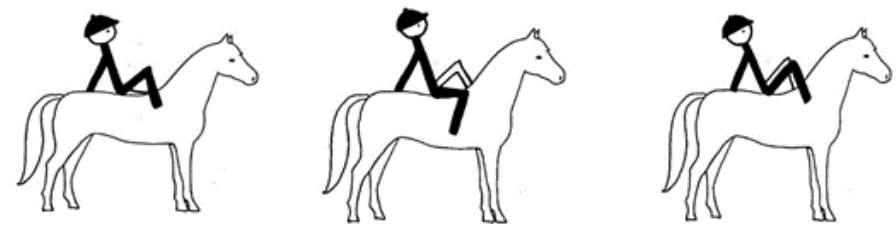

C
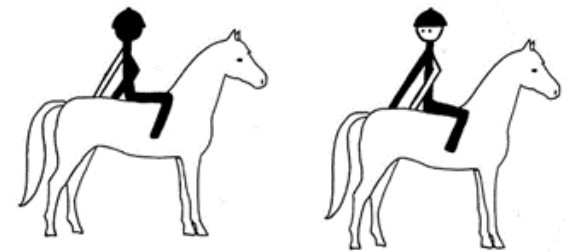

D
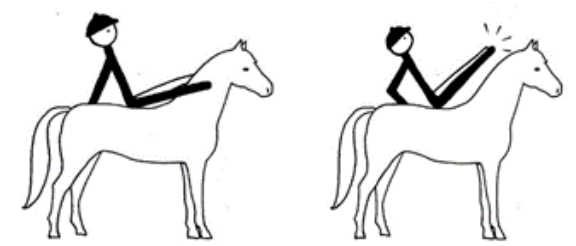

Figure 1. Exercises performed by probands from (A) the riding seat position. (B) Exercise 1, the elevation of the knees. (C) Exercise 2, rotation of the trunk. (D) Exercise 3, clapping the lower limbs. See the text for a detailed description. Drawing by Klára Pyšková.

Exercise 2 (rotation of the trunk) - the rotation of the trunk to the left, fry crosswise right (touch the left buttocks with the right palm) — turn the trunk back to the starting position-the rotation of the trunk to the right, fry crosswise with the left-turn the trunk back to the starting position 1C).

Exercise 3 (clapping the lower limbs) —flexion in both hip joints with extended knees in abduction—-bringing both feet together to clap—-moving both feet apart—lower limbs into the starting position (Figure 1D).

All exercises were performed on a living saddled horse in step (walking horse) and on a gymnastic horse, and the measured values of muscle activity were compared for both treatments. 


\subsection{Tested Muscles}

We chose musculus serratus anterior, $m$. erector spinae, $m$. obliquus abdominis externus and $m$. rectus abdominis for testing, as muscles that actively participate in maintaining the stability of the trunk during changes in body movement and riding seated position. All the muscles were tested bilaterally, and the following abbreviations are used in figures and tables: serr. ant. dx., serr. ant. sin., erector spinae dx., erector spinae sin., obliquus ext. dx., obliquus ext. sin., rectus abd. dx., rectus abd. sin.

\subsection{Electromyography: Measurement of Muscle Activity}

The muscle activity was measured electromyographically. A portable Biomonitor ME 6000 16* (Mega Electronics Ltd., Cambridge, UK) was used for the measurement (for more detailed specifications, see Figure S1). The device can process up to 16 channels simultaneously, and all channels are designed to receive signals from paired flat electrodes.

Special surface bipolar electrodes from Medico Lead-Lok were used to detect the signal. The electrodes were attached to the proband's well-cleaned skin on tested muscles, in parallel in the middle line of the muscular abdomen, and the ground electrode was placed according to the protocol of the Megawin program. Electrodes were not manipulated during the measurement. When gluing the electrodes, the proband was positioned in such a way that allowed the palpation of the examined muscle. The electrodes were attached directly onto the skin not to break the contact between the skin and the electrode, thus preventing signal interference by the movement of the electrodes [22]. Eight channels were used for the measurement: two for $m$. anterior serratus (dexter, sinister), two for $m$. rectus femoris (dexter, sinister), two for m. externus obliqus (dexter, sinister), and two for $m$. erector spinae (dexter, sinister). The data from the ME 6000 Biomonitor were processed using the MegaWin SW program.

The raw EMG signal was cut to record only the targeted movement we explored. The signal was then converted to the absolute value. After the conversion to the absolute value, before the actual thresholding (detection of the beginnings and ends of light activity), the course (electromyographic signal envelope) was smoothed by passing through the low-pass filter in the form of an FIR filter (including a moving average filter). Thus, we obtained the envelope by filtering the absolute value of the low-pass electromyographic signal. To suppress the delay of the signal when passing through the filter, we used a combination of the forward and backward filtration (filtrfilt function in Matlab). A lowpass filter with a cutoff frequency of $5.5 \mathrm{~Hz}$ and a non-pass band with an attenuation of approximately $107 \mathrm{~dB}$ starting at $8 \mathrm{~Hz}$ was used to calculate the envelope. The low-pass filter was implemented with an FIR filter with a length of 1501 coefficients at a sampling frequency of $1000 \mathrm{~Hz}$ [23].

All subjects were instructed not to consume alcohol, drugs, or other addictive substances $48 \mathrm{~h}$ before the experiment to avoid affecting their locomotor behavior. Before starting the measurement, each proband was informed about the exact course of the experiment and had enough time to try out the exercises without electrodes. Probands performed the exercises precisely according to the instructions. The exercise was explained and demonstrated to probands at the beginning of the experiment. Each proband then performed a trial exercise before conducting it on a gymnastic horse and a walking horse. The familiarization of the exercises ensured that all probands achieved adequate quality in all exercises during the experiment.

After being instructed, each proband practiced the exercises to eliminate execution errors. This was followed by the attachment of the electrodes and the configuration of the ME 6000 16*. Janda's strength muscle test [24] was then performed to determine maximum voluntary contractions (MVC), followed by measuring the muscle activity during all three exercises. Electrodes were not changed during the measurements.

All probands were measured under the same conditions in the gym and the riding facilities of the Premium Stables in Prague. The gymnastic and living horse sessions were performed on the same day. Each exercise was measured three times, and there was a 
one-minute break between each measurement and a two-minute break between different exercises. The interval between the sessions was $15 \mathrm{~min}$. Probands carried out exercises in a randomized order, first on the gymnastic horse, then on the living horse.

\subsection{Data Analysis and Processing}

The response variable was the activity of the selected muscles, expressed as the percentage value of MVC. The differences in muscle activity (expressed as the average from three replicate measurements) were tested by two-way analysis of variance (ANOVA) with treatment (gymnastics horse, walking horse) and sex (male, female) as factors.

\section{Results}

\subsection{Effect of Treatment: Gymnastic Horse vs. Walking Horse}

Muscle activity was statistically significantly affected by the factors studied (Hypothesis 1 ) in 9 cases out of 24 (= 3 exercises $\times 8$ muscles). The results of the statistical analysis comparing the involvement of muscles during exercise on both types of horses are shown in Table 1, measured values for all probands in Table S1. In 4 measured cases (i.e., $17 \%$ of the total number), when the type of treatment was significant, the involvement was always higher during the exercise on horseback in a step than on a gymnastic horse (Hypothesis 2 ). The respective cases refer to $m$. anterior dexter and $m$. sinister serratus in Exercise 1 , and m. oblique abdominis externus sinister and $m$. anterior sinister serratus in Exercise 2; during Exercise 3, the type of treatment had no significant effect.

Table 1. Summary of two-way ANOVAs testing the effect of factors treatment (horse: gymnastic vs. in step) and sex (male, female) on muscle activity (expressed as the \% MVC across three replicated measurements). Statistically significant results are shown: ${ }^{*} p<0.05{ }^{* *} p<0.01,{ }^{* *} p<0.001$, including marginally significant $(0.05>p<0.1)$, marked $\left({ }^{*}\right)$; n.s. = non-significant, $\mathrm{df}=1,14$; horse $\times$ sex $=$ interaction of both factors. For each significant test, the column Direction shows for which factor the higher value was recorded.

\begin{tabular}{|c|c|c|c|c|c|}
\hline Exercise & Muscle & Test & F-Value & $p$-Value & Direction \\
\hline Exercise 1 & $\begin{array}{l}\text { serr. ant. dx. } \\
\text { serr. ant. sin. } \\
\text { erector spinae dx. } \\
\text { erector spinae sin. } \\
\text { obliquus ext. dx. } \\
\text { obliquus ext. sin. } \\
\text { rectus abd. dx. } \\
\text { rectus abd. sin. }\end{array}$ & $\begin{array}{c}\text { factor horse } \\
\text { factor sex } \\
\text { horse } \times \text { sex } \\
\text { factor horse } \\
\text { factor sex } \\
\text { horse } \times \text { sex } \\
\text { factor horse } \\
\text { factor sex } \\
\text { horse } \times \text { sex } \\
\text { factor horse } \\
\text { factor sex } \\
\text { horse } \times \text { sex } \\
\text { factor horse } \\
\text { factor sex } \\
\text { horse } \times \text { sex } \\
\text { factor horse } \\
\text { factor sex } \\
\text { horse } \times \text { sex } \\
\text { factor horse } \\
\text { factor sex } \\
\text { horse } \times \text { sex } \\
\text { factor horse } \\
\text { factor sex } \\
\text { horse } \times \text { sex }\end{array}$ & $\begin{aligned} \mathrm{F} & =5.92 \\
\mathrm{~F} & =12.80 \\
\mathrm{~F} & =2.96 \\
\mathrm{~F} & =9.67 \\
\mathrm{~F} & =26.93 \\
\mathrm{~F} & =4.02 \\
\mathrm{~F} & =0.55 \\
\mathrm{~F} & =1.57 \\
\mathrm{~F} & =0.01 \\
\mathrm{~F} & =0.03 \\
\mathrm{~F} & =0.52 \\
\mathrm{~F} & =0.25 \\
\mathrm{~F} & =1.14 \\
\mathrm{~F} & =0.43 \\
\mathrm{~F} & =0.35 \\
\mathrm{~F} & =5.93 \\
\mathrm{~F} & =4.04 \\
\mathrm{~F} & =0.20 \\
\mathrm{~F} & =0.97 \\
\mathrm{~F} & =2.72 \\
\mathrm{~F} & =0.17 \\
\mathrm{~F} & =0.82 \\
\mathrm{~F} & =0.83 \\
\mathrm{~F} & =0.07\end{aligned}$ & $\begin{array}{c}<0.05^{* *} \\
<0.01^{* *} \\
\text { n.s. } \\
<0.01^{* *} \\
<0.001^{* * *} \\
\text { n.s. } \\
\text { n.s } \\
\text { n.s } \\
\text { n.s. } \\
\text { n.s } \\
\text { n.s } \\
\text { n.s. } \\
\text { n.s } \\
\text { n.s } \\
\text { n.s. } \\
<0.05{ }^{*} \\
0.06\left(^{*}\right) \\
\text { n.s. } \\
\text { n.s } \\
\text { n.s } \\
\text { n.s. } \\
\text { n.s } \\
\text { n.s } \\
\text { n.s. }\end{array}$ & $\begin{array}{l}\text { horse in step } \\
\text { female } \\
\text { horse in step } \\
\text { female }\end{array}$ \\
\hline
\end{tabular}


Table 1. Cont.

\begin{tabular}{|c|c|c|c|c|c|}
\hline Exercise & Muscle & Test & F-Value & $p$-Value & Direction \\
\hline \multirow[t]{24}{*}{ Exercise 2} & serr. ant. dx. & factor horse & $F=0.22$ & n.s & \\
\hline & & factor sex & $F=1.06$ & n.s & \\
\hline & & horse $\times$ sex & $\mathrm{F}=0.64$ & n.s. & \\
\hline & serr. ant. sin. & factor horse & $\mathrm{F}=0.40$ & n.s & \\
\hline & & factor sex & $\mathrm{F}=5.95$ & $<0.05$ * & female \\
\hline & & horse $\times$ sex & $\mathrm{F}=4.92$ & $<0.05^{*}$ & horse in step \\
\hline & erector spinae dx. & factor horse & $\mathrm{F}=1.90$ & n.s & \\
\hline & & factor sex & $F=0.03$ & n.s & \\
\hline & & horse $\times$ sex & $\mathrm{F}=0.62$ & n.s. & \\
\hline & erector spinae sin. & factor horse & $\mathrm{F}=0.30$ & n.s & \\
\hline & & factor sex & $\mathrm{F}=0.10$ & n.s & \\
\hline & & horse $\times$ sex & $\mathrm{F}=0.57$ & n.s. & \\
\hline & obliquus ext. dx. & factor horse & $\mathrm{F}=0.28$ & n.s & \\
\hline & & factor sex & $\mathrm{F}=0.02$ & n.s & \\
\hline & & horse $\times$ sex & $\mathrm{F}=0.75$ & n.s. & \\
\hline & obliquus ext. sin. & factor horse & $\mathrm{F}=0.17$ & n.s. & \\
\hline & & factor sex & $\mathrm{F}=12.84$ & $<0.01 * *$ & female \\
\hline & & horse $\times$ sex & $F=0.89$ & n.s. & \\
\hline & rectus abd. $\mathrm{dx}$. & factor horse & $\mathrm{F}=0.35$ & n.s & \\
\hline & & factor sex & $\mathrm{F}=0.37$ & n.s & \\
\hline & & horse $\times$ sex & $\mathrm{F}=0.11$ & n.s. & \\
\hline & rectus abd. sin. & factor horse & $\mathrm{F}=0.78$ & n.s & \\
\hline & & factor sex & $\mathrm{F}=1.40$ & n.s & \\
\hline & & horse $\times$ sex & $\mathrm{F}=0.03$ & n.s. & \\
\hline \multirow[t]{24}{*}{ Exercise 3} & serr. ant. $\mathrm{dx}$. & factor horse & $F=1.66$ & n.s. & \\
\hline & & factor sex & $\mathrm{F}=7.10$ & $<0.05^{* * *}$ & female \\
\hline & & horse $\times$ sex & $\mathrm{F}=0.95$ & n.s. & \\
\hline & serr. ant. sin. & factor horse & $F=2.65$ & n.s. & \\
\hline & & factor sex & $\mathrm{F}=29.02$ & $<0.001^{* * *}$ & female \\
\hline & & horse $\times$ sex & $\mathrm{F}=3.72$ & n.s. & \\
\hline & erector spinae $\mathrm{dx}$. & factor horse & $\mathrm{F}=3.18$ & n.s. & \\
\hline & & factor sex & $\mathrm{F}=0.53$ & n.s. & \\
\hline & & horse $\times$ sex & $\mathrm{F}=0.38$ & n.s. & \\
\hline & erector spinae sin. & factor horse & $\mathrm{F}=0.54$ & n.s. & \\
\hline & & factor sex & $\mathrm{F}=0.24$ & n.s. & \\
\hline & & horse $\times$ sex & $\mathrm{F}=0.42$ & n.s. & \\
\hline & obliquus ext. dx. & factor horse & $\mathrm{F}=0.71$ & n.s. & \\
\hline & & factor sex & $\mathrm{F}=0.97$ & n.s. & \\
\hline & & horse $\times$ sex & $\mathrm{F}=0.01$ & n.s. & \\
\hline & obliquus ext. sin. & factor horse & $\mathrm{F}=0.01$ & n.s. & \\
\hline & & factor sex & $\mathrm{F}=12.04$ & $<0.01^{* * *}$ & female \\
\hline & & horse $\times$ sex & $F=0.30$ & n.s. & \\
\hline & rectus abd. $\mathrm{dx}$. & factor horse & $\mathrm{F}=0.22$ & n.s. & \\
\hline & & factor sex & $\mathrm{F}=3.31$ & $\left.0.09{ }^{*}\right)$ & female \\
\hline & & horse $\times$ sex & $\mathrm{F}=0.01$ & n.s. & \\
\hline & rectus abd. sin. & factor horse & $\mathrm{F}=0.02$ & n.s. & \\
\hline & & factor sex & $F=2.51$ & n.s. & \\
\hline & & horse $\times$ sex & $\mathrm{F}=0.01$ & n.s. & \\
\hline
\end{tabular}

\subsection{Effect of Proband Sex}

The effect of the sex of the proband was significant or marginally significant in 9 out of 24 measured exercise/muscle combinations (i.e., in 38\% of cases). The significant results refer to $m$. serratus anterior dexter and sinister and $m$. obliquus abdominis externus sinister in Exercise 1, m. serratus anterior sinister and m. obliquus abdominis externus sinister in Exercise 2, and $m$. serratus anterior dexter and sinister, $m$. obliquus abdominis externus sinister and $m$. rectus abdominis dexter in Exercise 3. In all cases, a higher involvement was recorded in women. 


\subsection{Muscle Activity during Exercises}

In Exercise 1, the involvement of muscles on a gymnastic horse ranged between $48-106 \%$ and on the horse in step between $70-162 \%$ of MVC (Figure 2). The $m$. serratus anterior dexter was the least involved on the gymnastic horse and $m$. obliquus externus abdominis dexter was the most involved. On the horse in step as well as on the gymnastic horse, the smallest activity was recorded for $m$. erector spinae and the highest for $m$. obliquus externus abdominis dexter. The greatest difference in involvement was recorded in $m$. obliquus externus abdominis; in the case of sinister it was statistically significant (Table 1). Overall, in Exercise 1, muscle activity was higher on the horse in step treatment than on the gymnastic horse (Figure 2).
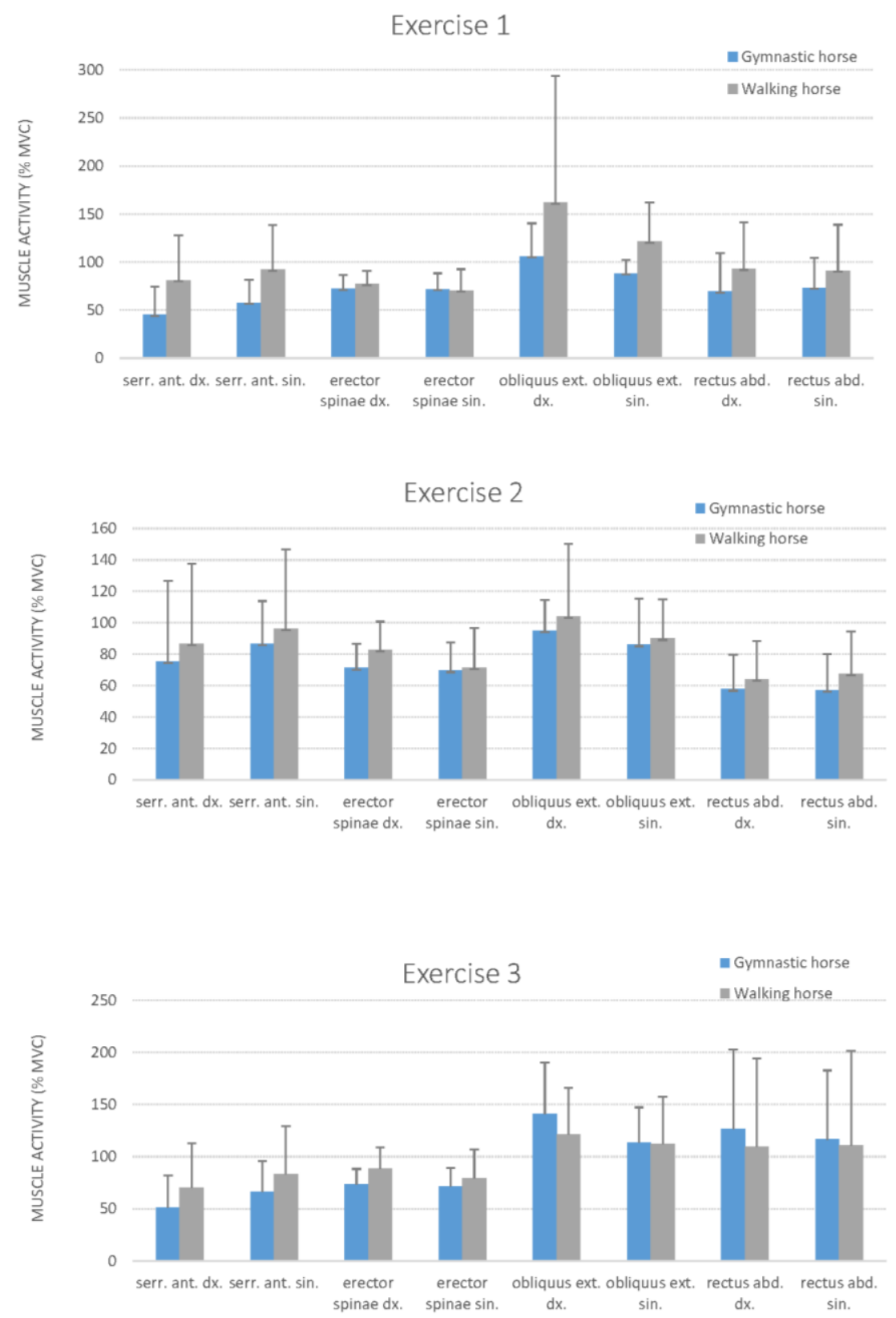

Figure 2. The activity of tested muscles (\% MVC) during the three exercises performed by probands on gymnastic vs. walking (in step) horse: Exercise 1, the elevation of the knees; Exercise 2, rotation of the trunk; Exercise 3, clapping the lower limbs. The values are averages of all probands $(n=9)$. See Methods for full muscle names. 
In Exercise 2 (Figure 2), muscle involvement ranged between $57-95 \%$ on the gymnastic horse and between $64-104 \%$ on the horse in step. The $m$. rectus abdominis sinister and dexter was the least involved on the gymnastic horse, and m. obliquus externus abdominis dexter was the most involved. The results on the horse in step were the same, except for $m$. rectus abdominis sinister, for which the result was not significant. The values recorded in Exercise 2 were consistently slightly higher on the horse in step than on the gymnastic horse (Figure 2), but a statistically significant difference was found only in $m$. serratus anterior sinister (Table 1).

In Exercise 3 (Figure 2), the involvement of muscles on the gymnastic horse ranged between $51-141 \%$ and on the horse in step between $70-121 \%$. On both the gymnastic horse and the horse in step, m. serratus anterior dexter was least active and $m$. obliquus externus abdominis dexter most active. Both groups of abdominal muscles were more involved on the gymnastic horse than on the horse in step. For other muscles, the activity was higher on the horse in step (Figure 2). However, the differences between the horse in step and the gymnastic horse were not statistically significant (Table 1).

\section{Discussion}

\subsection{Influence of the Studied Factors on Muscle Activity}

All hypotheses we tested were confirmed. The muscle involvement during exercises was affected by the studied factors. In general, muscle involvement was higher when probands performed exercises on the horse in step than on the gymnastic horse, and it was higher in women than in men. When performing Exercises 1 and 2 on the horse in step, some measurements showed a general tendency for greater muscle involvement than on the gymnastic horse; this does not apply to the abdominal muscles in Exercise 3, where the opposite trend was recorded. The values on the horse in step were consistently higher, although these differences were statistically significant in less than $20 \%$ of cases.

The highest tendency for increased muscle involvement (compared to the gymnastic horse) during step riding exercises was manifested bilaterally in the anterior serratus muscle during Exercises 1 and 2, the lowest in Exercise 3. The high $m$. serratus anterior activity, recorded bilaterally, can be explained by it being a stabilizing muscle whose activity is further increased by the fact that the horse represents an unstable base for probands-its movement irritates the control centers and forces a person to balance (i.e., to maintain the balance during rhythmic movement of the horse). This process leads to the activation of muscles and nerve pathways; consequently, the brain learns to evaluate and process the information about the movement of the body in space and control it back (so-called neurological learning [24]). At that moment, the stabilizing muscles develop a higher activity. Sitting on a horse in step also strongly influences the development of postural motor skills and muscles, especially the muscles of the trunk, abdominal muscles, diaphragm, muscles of the pelvic and shoulder girdle [25].

Another possible explanation for the higher activation of the serratus anterior muscle bilaterally compared to, for example, the abdominal muscles is that there is generally less subcutaneous fat in the serratus anterior region than in the abdomen. The thickness of the tissue between the electrodes and the activated muscle determines the properties of this tissue, as well as the amplitude of the EMG signal-the subcutaneous fat reduces the amplitude, hence, a higher body fat may skew the EMG measurement results [26].

The low activity in Exercise 3 can be explained by the fact that it was not performed precisely according to the instructions. A possible explanation is that the horse is stable in step, but it is an unstable base for the probands, and all probands were non-riders. Therefore, the fear of performing the exercise was apparent. Most probands, thus, ended the exercise with flexed knees, without the final phase of joining the extended lower limbs above the horse's neck. However, it is not only fear that affects the involvement of muscles when sitting on a horse in step. The seat is affected not only by biomechanical and physiological factors but also by psychogenic influences. Muscle activity is greatly affected by the mere contact with the horse and the opportunity to sit on its back. For this reason, 
exercising on a living animal is more beneficial than exercising on a gymnastic horse or barrel, which are very often used to practice correct riding-seat [14].

In $40 \%$ of cases, muscle activity was higher in women. When we consider only riding in step, women's muscle activity was higher in all cases, and these differences were statistically significant. A plausible explanation may be that women have to put more effort than men to stay on horseback. Again, it is necessary to consider the fear factor, where women, in general, are probably more afraid than men. Lehnert [27] states that women have $10 \%$ smaller muscle mass than men relative to their total body weight and that the level of muscle strength of women is about $2 / 3$ of that of men. The absolute maximum strength in women reaches $60-80 \%$ of male values [28]. This is confirmed by our results, when the values in the tested women, expressed as a percentage of the values measured in men, reached $60-90 \%$ of the maximum free capacity of men in most muscles.

\subsection{Methodological Implications}

In some cases, values above $100 \%$ MVC were recorded during the measurement (Figure 2). Because the values were standardized relative to MVC, this is a measurement artifact most likely due to a greater dynamic effort made by a proband during the exercise, whether on a gymnastic horse or a step horse. The muscle test uses standardized positions that cannot be achieved with complex movement. Thus, it can be concluded that a higher level of intermuscular coordination involves more motoric units, so the action potential is much greater when performing a movement. Janda's strength muscle test [24], which was performed when measuring MVC, does not allow isolated testing of a particular muscle, and when performing the tested movement, the force is distributed between the synergistic muscles, or the movement is compensated for by other muscles. Therefore, when measuring the MVC with a muscle test, the muscle does not show its maximum strength, which it is able to achieve independently. When performing the exercise, the muscle is involved to a greater extent, so the resulting values may exceed $100 \%$.

Although muscle activity during exercise on a gymnastic horse was generally lower than during exercise on a living horse, our results suggest that appropriate exercises off the live horse would contribute to the training of beginner riders. However, it is important to choose the proper exercises so that those muscles are involved, which are then most needed on the horseback riding to maintain a correct riding seat.

\subsection{Limitations to the Study}

There are some limitations to our study that need to be taken into account when interpreting the results and suggesting future research avenues. The main limitation is the relatively small sample size in terms of the number of probands, which may decrease the power of statistical tests. In addition, all probands performed their exercises on one horse which did not allow to consider variation in muscle activities related to horse movement dynamics. These limitations reflect that our study was a pilot one; for logistic reasons (limited time frame, funding, and scope of the original project), it was not possible to use as many horses as needed for allowing the statistical evaluation of 'horse' as a factor. We suggest that this can be improved in future studies.

\section{Conclusions: Avenues for Future Research}

Based on the results of the study, promising avenues of future research can be suggested. Given the recorded, statistically confirmed tendency for greater muscle involvement on the left side of the body, it would be beneficial to test laterality as a factor as well. All tested probands were right-handed, hence, they can be expected to have a greater muscle involvement of the left side-in the case of the dominant right limb, the left is used for stabilization. It would also be interesting to test the functionality of the deep stabilization system. However, such testing would have to be undertaken in two groups, i.e., riders vs. non-riders. In our opinion, the deep stabilization system is more involved in riders due to the unstable base on the horse in step than in non-riders. 
Riding is a very time-consuming and financially demanding sport, and if it were possible to improve the riding seat with the help of exercises with proven efficiency, it would mean a considerable benefit for beginner riders. If it turns out that there are exercises for which we are able to simulate the effect of a live horse, we could use these exercises in conjunction with physiotherapy.

Supplementary Materials: The following are available online at https:/ /www.mdpi.com/article/ 10.3390/app112311352/s1, Figure S1: Technical specification of Biomonitor ME 6000 16*. Table S1: Summary of measured values of muscle activity of all probands.

Author Contributions: B.P. and T.N. designed the study; B.P. and R.B. carried out the measurements; B.P. analysed the data and wrote the manuscript, and the other authors commented on it. All authors have read and agreed to the published version of the manuscript.

Funding: This reseatch was conducted as a part of the Q14 Biological Aspects of Human Movement programme at Charles University.

Institutional Review Board Statement: The study was conducted according to the guidelines of the Declaration of Helsinki and approved by the Institutional Review Board (or Ethics Committee) of Faculty of Physical Education and Sport, Charles University (protocol code 040/2017, approved on 3 August 2017).

Informed Consent Statement: Informed consent was obtained from all subjects involved in the study.

Data Availability Statement: The data associated with the paper are provided in Table S1.

Acknowledgments: We thank Jan Pergl for conducting the statistical analyses, Petra Hadlová for improving our English, and four anonymous reviewers for their comments. We also thank Prague Premium Stables and all the probands.

Conflicts of Interest: The authors declare no conflict of interest.

\section{References}

1. Hollý, K.; Hornáček, K. Hipoterapie—Léčba Pomocí Koně; Montanex: Ostrava, Czech Republic, 2005.

2. Goldmann, T.; Vilimek, M. Kinematics of human spine during hippotherapy. Comput. Methods Biomech. Biomed. Eng. 2012, 15 (Suppl. S1), 203-205. [CrossRef] [PubMed]

3. Hollý, K. Jezdectví pro Samouky; Montanex: Ostrava, Czech Republic, 2003.

4. Ritter, T. Artistics Dressage. Riding Hurts. Available online: http://www.classicaldressage.com/articles/hurts.html (accessed on 17 March 2021).

5. Willson, A. Horse Riding Excercises. Applied Posture Riding. Available online: http://dressageridertraining.com/blog/centralcore-muscles-involved-ride (accessed on 17 March 2021).

6. Willson, A. Horse Riding Posture. Applied Posture Riding. Available online: https:/ /www.appliedpostureriding.com.au/table/ articles/horse-riding-posture (accessed on 17 March 2021).

7. Véle, F. Úvaha nad hipoterapií. Rehabilitácia 2004, 41, 76-79.

8. Smith, N. 8 Key Muscles Involved When We Ride. Dressage Rider Training. Available online: http://dressageridertraining.com/ blog/central-core-muscles-involved-ride/ (accessed on 17 March 2021).

9. Guyton, A.C.; Hall, J.E. Textbook of Medical Physiology, 11th ed.; Elsevier Saunders: Amsterdam, NL, USA, 2006.

10. Dylevský, I. Speciální Kineziologie; Grada: Praha, Czech Republic, 2009.

11. Kolář, P. Rehabilitace v Klinické Praxi; Galén: Praha, Czech Republic, 2009.

12. Willson, A. The Horse Riding Muscles and How to Train Them. Ezinearticles. 2017. Available online: http:/ / ezinearticles.com/ ?The-Horse-Riding-Muscles-and-How-to-Train-Them\&id=4289743 (accessed on 17 March 2021).

13. Willson, A. When the Problem Rider Causes a Problem Horse. Ezinearticles. 2017. Available online: http:/ / ezinearticles.com/ ?The-Horse-Riding-Muscles-and-How-to-Train-Them\&id=4289743 (accessed on 17 March 2021).

14. Benda, W.; McGibbon, H.N.; Grant, L.K. Improvements in muscle symmetry in children with cerebral palsy after equine-assisted therapy (hippotherapy). J. Altern. Complement Med. 2003, 9, 817-825. [CrossRef] [PubMed]

15. Kim, H.S.; Lee, C.-W.; Lee, I.S. Comparison between the effects of horseback riding exercise and trunk stability exercise on the balance of normal adults. J. Phys. Ther. Sci. 2014, 26, 1325-1327. [CrossRef] [PubMed]

16. Daehee, L.; Sangyong, L.; Jungseo, P. Effects of indoor horseback riding and virtual reality exercises on the dynamic balance ability of normal healthy adults. J. Phys. Ther. Sci. 2014, 26, 1903-1905.

17. Lee, C.W.; Kim, S.G.; Na, S.S. The effects of hippotherapy and a horse riding simulator on the balance of children with cerebral palsy. J. Phys. Ther. Sci. 2014, 26, 423-425. [CrossRef] [PubMed] 
18. Park, E.S.; Rha, D.-W. Effects of hippotherapy on gross motor fiction and functional performance of children with cerebral palsy. Yonsei Med. J. 2014, 55, 1736-1742. [CrossRef]

19. Baek, I.H.; Kim, B.J. The effects of horse riding simulation training on stroke patients' balance ability and abdominal muscle thickness changes. J. Phys. Ther. Sci. 2014, 26, 1293-1296. [CrossRef] [PubMed]

20. Häkanson, M.; Möller, M.; Lindström, I.; Mattsson, B. The horse as the healer: A study of riding in patients with back pain. J. Bodyw. Mov. Ther. 2009, 13, 43-52. [CrossRef] [PubMed]

21. Ohtani, N.; Kitagawa, K.; Mikami, K.; Kitawaki, K.; Akiyama, J.; Fuchikami, M.; Uchiyama, H.; Ohta, M. Horseback riding improves the ability to cause the appropriate action (go reaction) and the appropriate self-control (no-go reaction) in children. Front. Publ. Health 2017, 5, 8. [CrossRef] [PubMed]

22. SENIAM. Surface ElectroMyoGraphy for the Non-Invasive Assessment of Muscles. Biomedical Health and Research Program (BIOMED II) of the European Union. 1999. Available online: http:/ / www.seniam.org (accessed on 17 March 2021).

23. Špulák, D.; Čmejla, R.; Bačáková, R.; Kračmar, B.; Satrapová, L.; Novotný, P. Muscle activity detection in electromyograms recorded during periodic movements. Comput. Biol. Med. 2014, 47, 93-103. [CrossRef] [PubMed]

24. Janda, V. Funkční Svalový Test; Grada: Praha, Czech Republic, 1996.

25. Nerandžič, Z. Animoterapie Aneb jak nás Zviřata Umí Léčit: Praktický Průvodce pro Veřejnost, Pedagogy i Pracovníky Zdravotnických Zařizení a Sociálních Ústavui; Albatros: Praha, Czech Republic, 2006.

26. Abbaspour, S.; Fallah, A. Removing ECG artifact from the surface EMG signal using adaptive subtraction technique. J. Biomed. Phys. Eng. 2014, 4, 33-38. [PubMed]

27. Lehnert, M. Trénink Kondice ve Sportu; Univerzita Palackého v Olomouci: Olomouc, Czech Republic, 2010.

28. Bernaciková, M. (Ed.) Výzkum ve Fyziologii Zátěže I; Masarykova univerzita: Brno, Czech Republic, 2013. 